\title{
Dyadic Coping Among Married Couples with Breast Cancer Survivor Wife
}

\author{
Thio Venny Purba ${ }^{1}$ Widya Risnawaty ${ }^{1 *}$ \\ ${ }^{1}$ Faculty of Psychology, Universitas Tarumanagara, West Jakarta 11440, Jakarta, Indonesia \\ "Corresponding author. Email: widyar@fpsi.untar.ac.id
}

\begin{abstract}
Breast cancer is a type of cancer that is commonly found in women. Breast cancer patients usually undergo a series of treatment processes to cure breast cancer within a certain period of time. The breast cancer patients can be affected both mentally and physically. When dealing with breast cancer, not only patients experience stress, but stress is also experienced by the families who take care for the patient. In particular, the husband acts as the first caregiver who immediately feels stress due to the wife's condition. This study aims to describe an overview of dyadic coping in couples whose wife has breast cancer. Dyadic coping is a partner's way of responding to stressful situations or problems that can lead to feelings of stress in the relationship. This research uses a qualitative approach with narrative research study. In-depth interviews were conducted with four couples of wives with breast cancer survivors. The results of this research showed that supportive dyadic coping and common dyadic coping with emotion-focused and problem-focused coping formed in married couples with breast cancer survivors. The study highlighted dyadic coping plays an important role in couples when dealing with stress when the wife has breast cancer. Communication, personality, household pattern, economy, and social support factors affecting dyadic coping were discussed.
\end{abstract}

Keywords: Dyadic coping, dyadic stress, breast cancer survivor, married couples, qualitative approach, narrative study

\section{INTRODUCTION}

Cancer is a disease which is caused by the development of an abnormal cell due to imbalance of body cells. The abnormal cells develop into tissue that can cause morbidity and will lead to death if left untreated [1]. However, cancer is a dreaded disease, cancer has a high mortality rate. World Health Organization [2] reported in 2018, cancer is in the second position of world top diseases causes of death. According to Globocan [3] at least 1 in 8 men and 1 in 11 women are expected to die from cancer.

In women, breast cancer is a malignant cancer and experienced by most women. There are $12 \%$ chances a woman will develop breast cancer during her lifetime [4]. Breast cancer generally develops from the epithelium that lines mammary glands [5]. Hormones, reproduction, dietary, physical activity, and radiation during breast development are the several risk factors that can trigger breast cancer development in the body [1].

Patients of breast cancer are often associated with pain and suffering. Breast cancer not only affects the patient in the medical, but also affects in psychological and social [6]. Patients of breast cancer usually experienced high stress starting from the initial process of diagnosis until the process of treatment and healing. Compas and Luecken [7] have shown that patients of breast cancer have increased negative emotions and also linked with psychological distress, such as depression and anxiety disorder. Women with breast cancer showed a poor significant impact on their quality of life and emotions [8]. This statement is reinforced by previous studies that indicate women with breast cancer were detected to experience negative impacts on various aspects of life, such as relationships with others, expectations of life, productivity, long-term plans, and social. When patients are struggling to heal themselves from breast cancer, not only do they experience stress, but stress is also experienced by the families who take care for the patient [9]. In particular, in married couples, husbands become the first caregiver. Husbands of the patients with breast cancer experience higher psychological stress than patients [10], the stress can be caused by the husband's fear of losing his wife, and husband's extra roles in providing support and taking care of his wife [11]. In married couples, when one partner experiences individual stress, directly or indirectly the stress will have an impact on the other partner along with the inability of one partner to cope with it [12]. Breast cancer can be a dyadic stressor in couple's relationships, the patients of breast cancer will experience stress because of the pain, and the partner will experience stress because they have to adapt with the disease that was experienced by his partner [13]. Zimmermann [11] stated couples with a wife who has breast cancer can experience mutual stress, fear, depression, and anxiety and this is known as dyadic stress. Dyadic stress is any form of stress, 
whether it focuses on emotions or the problems that are faced by a partner as a unit [12]. Couples who have a wife with breast cancer have to cope, relieve, and control stress by using a coping strategy [14], coping strategy that is used by couples is called dyadic coping [12]. Bodenmann [12] explained dyadic coping as a process that occurs when one partner in a relationship gives a stress signal and the other partner responds to the stress signal with a coping reaction. Dyadic coping is not seen as altruistic behavior, but is a couples strategy to balance their relationship from the negative impacts of stress. Dyadic coping makes the relationship more positive and better when dealing with stress [15].

This study aims to identify and describe dyadic coping among married couples with a breast cancer survivor wife. Focus of this study to describe an overview of dyadic coping when a partner is going through a stressful period when his wife is suffering from breast cancer. This study also wants to see the impact of dyadic coping on the relationship of the couple, in terms of the relationship between the couple before the wife was sick, when the wife was sick, and after the wife recovered from breast cancer. Research in this field is still relatively new and limited. This research aims to be able to contribute in this field and for further research.

\subsection{Related Work}

Dyadic coping research has contributed to married couples, in particular the research has found contributed in relationship quality, marital satisfaction, marital well-being, and relationship functioning [16]-[18]. Recent years, dyadic coping has increasingly focused on couples' efforts to cope with stress caused by chronic illness [19]-[22]. Today, dyadic coping not only focuses on both partners, but also other people who are related to partners, for example children [23].

\subsection{Our Contribution}

This paper presents an overview of dyadic coping among couples with a breast cancer survivor wife. Research on this paper can be applied in clinical psychology and family psychology.

\subsection{Paper Structure}

The rest of the paper is organized as follows. Section 2 introduces the grand theory that was used in this paper, which is dyadic coping theory. Section 3 presents methods that used to collect data for this research. Then, finding and discussion of dyadic coping among couples with a breast cancer survivor wife in Section 4. Finally, Section 5 concludes the paper and presents direction for future research.

\section{BACKGROUND}

\subsection{Dyadic Coping}

In the late 1980s, Bodenmann [15] and his group began research on stress and its impact on partner relationships. During 15 years of research in this field, researchers found that there is empirical evidence that stress is not associated with quality and satisfaction of partner relationships. Various findings show that stress is closely related to failure in relationships, for example resulting in poor communication and poor marriage satisfaction. Until, Bodenmann [15] and his group identified a new factor that influenced partner's behavior in periode of stress which was later called by dyadic coping. Dyadic coping theory develops based on Lazarus and Folkman's theory, namely the transactional stress theory [15].

Bodenmann [24] explained that dyadic coping occurs through several processes, such as: (a) partner experiencing stress gives a stress signal to his/her partner, (b) the partner perceives stress signals, and (c) responds to the signal that given by his/her partner. The concept of dyadic coping is not limited to how partners create behavior to deal with stress, but also about how partners share stressors and communicate stress [25].

Bodenmann et al. [26] stated that positive dyadic coping and negative dyadic coping are the two major forms of dyadic coping. Positive dyadic coping is divided into supportive dyadic coping, common dyadic coping, and delegated dyadic coping. Supportive dyadic coping occurs when one person in a partner helps his partner in coping when dealing with stress [27]. Common dyadic coping is coping strategy when both partners are involved in seeking information to solve problems, sharing and doing activities together [12]. Delegated dyadic coping occurs when one partner takes responsibility on a task from another partner to reduce the stress of the partner [27]. Furthermore, the negative form of dyadic coping is divided into several types, there are hostile dyadic coping, ambivalent dyadic coping, and superficial dyadic coping. Hostile dyadic coping is a condition when one of the people in couples provide support to their partner, but is accompanied by negative actions such as insulting and sarcasm [27]. The second form of negative dyadic coping is ambivalent dyadic coping, which is dyadic coping that occurs when a partner provides support to reduce stress, but the support provided is not optimal or the partner does not have enough energy, so the goal to reduce partner stress is not well conveyed [26]. The last form of negative dyadic coping is called superficial dyadic coping. This form occurs when a partner who provides support without motivation and empathy [26].

\section{METHODS}

\subsection{Participants and Procedure}

This research used a qualitative approach with narrative study, enabling understanding dyadic coping among 
married couples before the wife was sick, when the wife was sick, and after the wife recovered from breast cancer. In-depth interviews and observations were conducted with four couples. Number of participants based on Plummer in Creswell [28], who recommends at least two participants to conduct a narrative study. Participants were collectedusing purposive sampling. Purposive sampling is a technique in selecting samples, in which the researchers uses various methods to find all possible cases from a very specific and difficult population [29].

The study was conducted in Indonesia with participants who matched with the research criteria. The study is not demographically demarcated. The eligibility couples criteria in this research include: (1) couples who are 25 - 60 years old of age; (2) couples in a monogamous marriage; (3) lives in Indonesia; (4) the wife of the married couple is a breast cancer survivor. An individual who can be said to be a breast cancer survivor is an individual who has been diagnosed with breast cancer at least once in his life, lives with the disease, goes through various treatment processes, until she is cured from breast cancer [30]. Breast cancer survivors are individuals who have been through surgery and have gone through a treatment process, such as chemotherapy or radiation [31].

The research was conducted by collecting data through indepth interviews. The instruments used in this study were interview guides, observation sheets, informed consent, recorder, cell phones, and laptops. The interview was conducted online, using video call or voice call. Application media used in this study were Whatsapp video calls, Whatsapp calls, Zoom video calls, and phone calls. Data were collected through interviews with four couples or eight subjects separately. The researchers began to build a rapport with each participant in the initial interview. During the interview, the researchers conducted observations with the participants. Researchers observe the expressions and intonation of the participants. During the interview, researchers collected information on demographic characteristics (age, race, religion, education, occupation, and length of marriage), and information related to breast cancer (diagnosis and treatment). See Table 1 and Table 2 for more detailed participant demographic characteristics and information related to breast cancer. The interview was recorded and then transcribed verbatim by the researchers.

Table 1 Participant demographic characteristics

\begin{tabular}{|c|c|c|c|c|c|c|c|c|}
\hline \multirow[b]{2}{*}{ Characteristics } & \multicolumn{2}{|c|}{ Couples 1} & \multicolumn{2}{|c|}{ Couples 2} & \multicolumn{2}{|c|}{ Couples 3} & \multicolumn{2}{|c|}{ Couples 4} \\
\hline & Husband & Wife & Husband & Wife & Husband & Wife & $\begin{array}{c}\text { Husban } \\
\text { d }\end{array}$ & Wife \\
\hline Initial & NS & $\mathrm{MM}$ & SYW & YS & CAS & CDP & $\mathrm{TP}$ & $\mathrm{R}$ \\
\hline Gender & Man & Woman & Man & Woman & Man & Woman & Man & Woman \\
\hline Age & 45 & 42 & 57 & 53 & 42 & 42 & 60 & 55 \\
\hline Religion & Muslim & Muslim & Christian & Christian & Muslim & Muslim & Christian & Christian \\
\hline Race & Indonesian & $\begin{array}{c}\text { Indonesi } \\
\text { an }\end{array}$ & Chinese & Chinese & Indonesian & $\begin{array}{c}\text { Indonesi } \\
\text { an }\end{array}$ & $\begin{array}{l}\text { Indonesi } \\
\text { an }\end{array}$ & Indonesian \\
\hline Education & $\begin{array}{l}\text { Under- } \\
\text { graduate }\end{array}$ & Diploma & $\begin{array}{l}\text { High } \\
\text { School }\end{array}$ & Diploma & Diploma & $\begin{array}{l}\text { Junior } \\
\text { School }\end{array}$ & $\begin{array}{l}\text { High } \\
\text { School }\end{array}$ & High School \\
\hline Occupation & Employee & $\begin{array}{c}\text { Entrepre } \\
\text { neur }\end{array}$ & $\begin{array}{c}\text { Entreprene } \\
\text { ur }\end{array}$ & - & Employee & $\begin{array}{c}\text { Entrepre } \\
\text { neur }\end{array}$ & - & - \\
\hline $\begin{array}{l}\text { Length of } \\
\text { marriage }\end{array}$ & $17 \mathrm{y}$ & & $27 \mathrm{y}$ & & $17 \mathrm{y}$ & & & years \\
\hline
\end{tabular}


Table 2 Information related to breast cancer

\begin{tabular}{ccccc}
\hline Information & Couples 1 & Couples 2 & Couples 3 & Couples 4 \\
\hline Year of diagnosis & 2015 & 2016 & 2017 & 2020 \\
Stadium & $1 \mathrm{~b}$ & 2 & $2 \mathrm{~b}$ & - \\
Grade & 3 & - & 1 & - \\
\hline
\end{tabular}

\subsection{Data Analysis}

After obtaining sufficient data from the interview, the researchers began data processing and analysis. Form of data from this qualitative research is recorded interviews with the subjects that turns into a verbatim transcript. The current study focuses on the Clandinin and Connelly in Creswell approach [28] in data processing and analysis. The current study focused on the three elements of the participant's story about the participant's personal and social relationship when the partner suffered from breast cancer until partner was cured, the story of the couple's experience from initial diagnosis to recovery, and the situation faced by the couple in a state of illness to recovery from breast cancer. The researchers redraws the stories in chronological order.

After processing the data, the researchers in this narrative approach carried out the following stages of analysis, specifically: (a) identification of epiphanies or turning points, and the contextual of the participant story; (b) interpretation meaning of the whole story; (c) writing the narrative of the partilcipant's story [28]. Writing an analysis of the participant's story needs to pay attention to several important things [28]. First, the life process of couples. Second, dyadic coping theory which is related to the phenomena experienced by couples. Third, the overall story and uniqueness of the couple's story.

\section{FINDINGS AND DISCUSSIONS}

The results of this study presented the stories of the four couples. The findings of the study indicated that there are dyadic coping dynamics in all four couples with a breast cancer survivor wife.

\subsection{Couple 1: MM and NS}

Couple MM and NS were getting married in 2003. After getting married they lived together. Before NS was diagnosed from breast cancer, the relationship between MM and NS did not have a serious problem. This was stated by NS, who said Ee .. I feel Alhamdullilah Ma'am ee, as I see our marriage from the beginning ... was never have a significant problem, ...

The life of MM and NS at that time was fine and good. There are no stressors or pressures that exist in their relationship. In a relationship, stress experienced by just one partner is called indirect dyadic stress, while stress experienced directly by both partners is called dyadic stress (Bodenmann, 2015). Before NS suffering from breast cancer, MM and NS did not feel any indirect dyadic stress or dyadic stress in their relationship. Until 2015, when NS was taking a shower, NS accidentally touched her right breast and found that there was a lump. At that time, NS immediately panicked and thought that she had breast cancer. After bathing, NS immediately told MM about the lump that she found. MM and NS jointly looked for information on the internet about the lump, hospital, and doctor who could treat cancer.

Finally, MM and NS went to the doctor and NS was diagnosed from breast cancer. When NS was diagnosed with breast cancer, MM and NS began to notice there was dyadic stress in their relationship. MM and NS were feared, shocked, and worried about NS disease. After being diagnosed with breast cancer and NS undergoing the treatment process, NS became a private person and she lost her confidence. This was stated by NS, Uh, if there is no change in my husband's attitude. I shut myself up.

Both partners start to form dyadic coping in their relationship, such as supportive dyadic coping and common dyadic coping. Dyadic coping aims to bring both partners in a relationship to reduce the negative effects of stress, and increased mutual trust in couples [25]. Supportive dyadic coping shown by MM by providing support and giving important information about NS's disease. Common dyadic coping shown by the quality time between MM and NS that formed when NS was sick. After NS recovered from breast cancer, the relationship between the MM and NS became better than before. Dyadic coping that performed by MM and NS when NS diagnosed from breast cancer, succeeded in bringing the relationship to a better direction. The fear of loss arises from MM and MM changes his attitude and becomes someone who is more enjoyable and fun with his wife.

\subsection{Couple 2: SYW and YS}

When SYW and YS were getting married in 1993, they live together and built family business together. The marriage of SYW and YS went harmoniously, even though sometimes they got a little conflict. Dyadic coping began to form in couple 2, when YS was diagnosed from breast cancer. At first, YS went to the hospital alone and she felt indirect 
dyadic stress. Indirect dyadic stress is type of stress that perceived by one person in a relationship [32]. YS felt indirect dyadic stress when heard diagnosed from the doctor, she was shocked and cried. After that, she went back to home and told her husband about the diagnosed. Both of them felt dyadic stress, SYW and YS perceived stress because of the YS's disease. Supportive dyadic coping was the first type of dyadic coping that formed in couple 2 . This type of dyadic coping was made by SYW, he supported YS through his actions by told YS with encouraging words, take care of YS's feeling, and he do not want to drag on sadness so he can focused on YS's condition.

Common dyadic coping occurs when both partners perceive stress and dealing with it together [27]. During the treatment, SYW experienced economic constraints. Partners helped each other to overcome this situation. And also another form of common dyadic coping in SYW and YS relationship, when YS was sick they hired a household assistent to reduce YS's work.

After YS underwent various treatment processes, YS recovered from breast cancer disease. After recovering, both partners have a better and closer relationship.

\subsection{Couple 3: $C A S$ and $C D P$}

CAS and CDP were a married couple from Bogor, Indonesia. They had three daughters. Before CDP was diagnosed from breast cancer, this small family already had economic constraints. CDP stated that at the beginning of her marriage, she already knew that CDP needed to have a strong mental. At that time, CAS must have lived separately with CAS because CAS had worked in a different city. CAS's decisions to lived in different cities with CAS was a form of supportive dyadic coping. Dyadic coping was demonstrated by CAS before CDP was diagnosed from breast cancer.

In 2017, CDP felt like she had a cold but she ignored it. Over time, CDP accidentally touched her breasts and found a lump. However, CDP was still ignored and assumed that it was a common urinary disease. Day by day, CDP felt that the lump was getting wider, until finally CDP's friend asked her to go to the hospital. CDP did an ultrasound examination, the results showed a lump so that the doctor who handled CDP asked CDP to do a biopsy operation. After the operation, CDP was diagnosed with breast cancer. The reaction was shocked, but CDP did not become discouraged and cried. At the time when CDP was diagnosed with breast cancer, CAS was in a different city, and CDP kept her disease as a secret from her partner for nearly a week. The reason was because CDP did not want to put another burden on her partner's mind, and CDP told CAS about the disease when she thought the situation was better. In the end, CDP decided to tell her husband about her illness. When hearing that, CAS spontaneously cried and finally both of them cried. This situation was included as dyadic stress, in which CAS and CDP perceive the stress together and send stress signals to each other.

While CDP undergoes treatment processes, dyadic coping was performed by both partners. CAS provided support with verbal actions. In Bodenmann's theory [12], the behavior and actions of CAS are referred to as positive supportive dyadic coping with type of emotion-focused coping.

.... So, maybe if I'm feeling nauseous, at most I'm told to get a lot of rest, then I also like it a bit, yes, it's a normal situation in humans, sometimes there are times I like a bit stressed out, depressed, because my hair bald, so that's bald, my husband said, 'it's okay the important one is your health,

the hair will grow again'. Most of all, my husband always gave support to me.

Another supportive dyadic coping with a type of emotionfocused coping performed by CAS when CAS would never leave CDP, even though his partner was not as perfect as the first time they met. However, CAS never left CDP and patiently supported the CDP treatment process. Dyadic coping that was formed when CDP had breast cancer brought a positive change in CAS. After CDP recovered, the relationship between the partners became better than before. Actions that were initially performed as dyadic coping reactions during times of stress were still carried out even after CDP had recovered. One example is common dyadic coping, which is when the couple agrees that CAS do more work like cleaning the house.

\subsection{Couple 4: TP and $R$}

TP and R are a couple who have been bound together through a marriage since 1990 . According to subject R, her husband is someone who is very kind and very affectionate to her. Before the existence of stressors such as chronic illness in the relationship of TP and R, common illnesses can become a stressors so that couples showed a positive supportive dyadic coping with problem-focused coping in their relationship [27]. TP immediately wanted to help his wife to complete the housework when his wife was sick.

According to Strong et al. [33] the functions of marriage is cooperation between partners in the economy and other aspects. This function is shown in the relationship of TP and $\mathrm{R}$, both of them work together and have good cooperation with the housework.

When subject $\mathrm{R}$ was diagnosed with breast cancer in 2010 , both of the partners felt dyadic stress. It is shown by both partners' reactions that fear of R's disease. At the beginning, there was an obstacle in delivery of stress signals by subject $\mathrm{R}$ to subject TP because of the contextual factors. However, in the end dyadic coping can be done well by couple 4 . Even their dyadic coping had a good impact on the relationship after a stressful period, namely after $\mathrm{R}$ subjects recovered from breast cancer. Types of dyadic coping performed by this couple are supportive dyadic coping and common dyadic coping. In contrast with other couples, supportive dyadic coping in this couple was not only shown by the partner who was indirectly experiencing stress, but also by the partner who immediately experienced stress (subject R). 


\section{CONCLUSIONS}

In conclusion, results of this research show that the four couples performed dyadic coping with the wife of the couples being a breast cancer survivor. All partners showed dyadic stress when their partners were diagnosed with breast cancer. Feelings of pressure or stress are not only experienced by one party, but also experienced by both partners in the relationship. This can be seen from all the reactions of couples who felt shocked and full with sadness when they found out that their partner has breast cancer. As a result of the dyadic stress, the four partners performed dyadic coping in their relationship.

Types of dyadic coping with supportive dyadic coping and common dyadic coping were shown in all couples. The difference is in the type of coping that is more prominent and is often used by couples. Delegated dyadic coping did not appear in all four pairs, this is because neither partner directly assigned their partner to take over the partner's duties. In all couples, the husband immediately takes over household duties or employs a household assistant to help with the work and responsibilities of the wife without being asked by the wife.

Communication is an important factor in dyadic coping [25]. In two couples in this study, there were obstacles in performing dyadic coping due to communication problems. Personality factors and household relationship patterns also become the factors that affect a person in performing dyadic coping. Leszko [34] states that a person's personality affects coping strategies. Household relationship patterns affect couples' decision on choosing the type of dyadic coping. Some couples show more concern and help in household duties from the beginning of the marriage, this form of assistance continues until the time the wife has breast cancer and until now. The theory of this finding was not found in previous research yet, so further research is needed to examine the factors of household relationship patterns that affect couples on performing types of dyadic coping. Economic also play roles in dyadic coping, it shows that different condition of economy in partners delivered different type of dyadic coping. Social support plays an important role in partner's dyadic coping.

From this research, it can be concluded that dyadic coping leads couples to a better relationship. There is a change in the attitude of the partner after couples go through a period of stress and form a dyadic coping reaction. Couples who successfully perform dyadic coping can have a better, healthier, and more satisfying relationship.

\section{ACKNOWLEDGMENT}

Researchers would like to thank to everyone who has contributed to this research. Thank to teachers for guidance and for the support. Researchers would also like to express deep gratitude to participants for the participation and assistance in this paper.

\section{REFERENCES}

[1] R. W. Ruddon, Cancer Biology (4th ed.). Oxford University Press, 2007.

[2] World Health Organization, "Cancer regional profile $2020, " 2020$

[3] Globocan, "Indonesia,” 2018.

[4] American Cancer Society, "Cancer facts and figures $2015, " 2015$

[5] F. Bunz, Principles of cancer genetics. Springer, 2008 .

[6] A. A. Malik and T. Kiran, "Psychological problems in breast cancer patients: A review," Chemother. Open Access, vol. 2, no. 2, pp. 1-6, 2013.

[7] B. E. Compas and L. Luecken, "Psychological adjustment to breast cancer," Curr. Dir. Psychol. Sci., vol. 11, no. 3, pp. 111-114, 2002.

[8] D. Di Giacomo, K. Cannita, J. Ranieri, V. Cocciolone, D. Passafiume, and C. Ficorella, "Breast cancer and psychological resilience among young women," J. Psychopathol., vol. 22, no. 3, pp. 191-195, 2016.

[9] K. P. Mukwato, P. Mweemba, M. K. Makukula, and M. M. Makoleka, "Stress and copingmechanisms among breast cancer patients and family caregivers: A review of literature," Med. J. Zambia, vol. 37, no. 1, pp. 40-45, 2010.

[10] I. Hasson-Ohayon, G. Goldzweig, M. Braun, and D. Galinsky, "Women with advanced breast cancer and their spouses: Diversity of support and psychological distress," Psychooncology., vol. 19, no. 11, pp. 11951204, 2010.

[11] T. Zimmermann, "Intimate relationships affected by breast cancer: Interventions for couples," Breast Care, vol. 10, no. 2, pp. 102- 108, 2015.

[12] G. Bodenmann, "Dyadic coping: A systemictransactional view of stress and coping among couples: Theory and empirical findings," Eur. Rev. Appl. Psychol. / Rev. Eur. Psychol. Appliquée, vol. 47, no. 2, pp. 137141, 1997.

[13] M. J. Traa, J. De Vries, G. Bodenmann, and B. L. Den Oudsten, "Dyadic coping and relationship functioning in couples coping with cancer: A systematic 
review," Br. J. Health Psychol., vol. 20, no. 1, pp. 85$114,2014$.

[14] R. S. Feldman, Essentials of understanding psychology, 11th ed. McGraw-Hill Education, 2015.

[15] G. Bodenmann, "Dyadic coping and its significance for marital functioning.," Zeitschrift für Gesundheitspsychologie, vol. 16, no. 3, pp. 108-111, 2008.

[16] G. Bodenmann, N. Meuwly, and K. Kayser, "Two conceptualizations of dyadic coping and their potential for predicting relationship quality and individual wellbeing: A comparison," Eur. Psychol., vol. 16, no. 4, pp. 255-266, 2011.

[17] C. J. Breitenstein, A. Milek, F. W. Nussbeck, J. Davila, and G. Bodenmann, "Stress, dyadic coping, and relationship satisfaction in late adolescent couples," $J$. Soc. Pers. Relat., vol. 35, no. 5, pp. 770-790, 2018.

[18] L. M. Papp and N. L. Witt, "Romantic partners' individual coping strategies and dyadic coping: Implications for relationship functioning," J. Fam. Psychol., vol. 24, no. 5, pp. 551-559, 2010.

[19] C. Acquati and K. Kayser, "Dyadic coping across the lifespan: A comparison between younger and middle-aged couples with breast cancer," Front. Psychol., vol. 10, pp. 1-18, 2019.

[20] H. Badr, C. L. Carmack, D. A. Kashy, M. Cristofanilli, and T. A. Revenson, "Dyadic Coping in Metastatic Breast Cancer," Heal. Psychol., vol. 29, no. 2, pp. 169-180, 2010.

[21] V. Sallay, T. Martos, S. L. Chatfield, and A. Dúll, "Strategies of dyadic coping and self- regulation in the family homes of chronically ill persons: A qualitative research study using the emotional map of the home interview method," Front. Psychol., vol. 10, pp. 1-16, 2019.

[22] D. Tkachenko, L. Franke, L. Peters, M. Schiffer, and T. Zimmermann, "Dyadic coping of kidney transplant recipients and their partners: Sex and role differences," Front. Psychol., vol. 10, pp. 1- 13, 2019.

[23] M. Zemp, G. Bodenmann, S. Backes, D. SutterStickel, and T. A. Revenson, "The importance of parents' dyadic coping for children," Fam. Relat., vol. 65, no. 2, pp. $275-286,2016$.

[24] G. Bodenmann, "A systemic-transactional conceptualization of stress and coping in couples," Swiss J. Psychol., vol. 54, no. 1, pp. 34-49, 1995.
[25] A. K. Randall and S. Messerschmitt-Coen, "Dyadic coping as relationship maintenance," in Relationship maintenance: Theory, process, and context, B. G. Ogolsky and J. K. Monk, Eds. Cambridge University Press, 2019, pp. 178-193.

[26] P. Y. Herzberg and S. Sierau, "Dyadic coping in german couples," in Couples coping with stress: A crosscultural perspective, M. K. Falconier, A.

K. Randall, and G. Bodenmann, Eds. Routledge, 2016, pp. $122-136$

[27] G. Bodenmann, "Dyadic coping and its significance for marital functioning," in Couples coping with stress: Emerging perspectives on dyadic coping, T. A. Revenson, K. Kayser, and G. Bodenmann, Eds. American Psychological Association, 2005, pp. 33-50.

[28] J. W. Creswell, Qualitative inquiry and research design: Choosing among five approaches, 2 nd ed. Sage Publications, 2007.

[29] W. L. Neuman, Social research methods: Qualitative and quantitative approaches, 7 th ed. Pearson Education Limited, 2014.

[30] World Cancer Research Fund and American Institute for Cancer Research, "Diet, nutrition, physical activity and breast cancer survivors," 2018.

[31] B. Yan et al., "Determinants of quality of life for breast cancer patients in Shanghai, China," PLoS One, vol. 11 , no. 4, pp. 1-14, 2016.

[32] G. Bodenmann, "Illness and dyadic coping," in International encyclopedia of the social \& behavioral sciences: Second edition, 2 ed., J. D. Wright, Ed. Elsevier, 2015, pp. 593-59. 